\title{
Health Needs of Patients with Cholelithiasis Undergoing Laparoscopic Cholecystectomy
}

\author{
Sanaa Mohamed Alaa Eldin, Amna Yehia saad and Samira Saad Ali Abo El baka \\ Medical -Surgical Nursing Department, Faculty of Nursing, Alexandria University.
}

\begin{abstract}
Background: Laparoscopic cholecystectomy is standard procedure for management of gallbladder stone. Gallstones (cholelithiasis) are the most common cause of biliary tract disease in adults. The educative role of nurse is integral part of the care that is essential to patient satisfaction and positive outcomes.

Objective: Identify health needs of patients with cholelithiasis who were undergoing laparoscopic cholecystectomy.

Patients and Methods: A convenient sample of 100 adult patients with cholelithiasis who were undergoing laparoscopic cholecystectomy. Health needs of patients with cholelithiasis who were undergoing laparoscopic cholecystectomy included structured interview schedule was used to collect the data for the present study. It included two parts about socio-demographic and clinical data, knowledge related to nature of the disease, pre- operative preparation, post-operative care and self- care following discharge.

Results: the present study revealed that the majority of the studied patients had poor level of knowledge. There was statistically significant positive correlation between patients' level of knowledge and age, educational level, nurses as a source of knowledge and advices as well as physician and the nurse as a preferred source of knowledge.

Conclusion: It was concluded that the studied patients had poor level of knowledge regarding disease nature, pre-operative care, post-operative care and complications and self-care following discharge.

Keywords: Health Needs, Cholelithiasis, Laparoscopic Cholecystectomy
\end{abstract}

\section{Introduction}

Laparoscopic cholecystectomy (LC) is the removal of the gallbladder using a laparoscopic technique. It is considered the Gold standard treatment for symptomatic gallstone disease. It is considered one of the most common surgical procedures in western world. It has many advantages over open cholecystectomy in terms of minimal postoperative pain, shorter hospital stay, early recovery, a rapid return to work, less intra-abdominal adhesion, a better cosmetic outcome and decrease in perioperative septic complications ${ }^{(1)}$. The educative role of nurses facilitate emancipation and empowerment as patient gain confidence with self-care and provision of information by nurses, as sist patient and families to cope with surgical procedure, promoting participation and creating supportive and educative environment ${ }^{(2)}$.

Health needs of patients undergoing laparoscopic cholecystectomy including provision of information related to preoperative education, which is an important part to improve post- operative period and prevent post-operative complications. In addition, provision of information related to postoperative period includes post-operative pain management, exercise, nutrition, activity and follow up for evaluation of the care. This post-operative care is very important to prevent post-operative complications that lead to post-operative mortality and prolonged hospital stay, decrease functional and cognitive status and has a huge impact effect in hospital costs ${ }^{(3)}$.

The aim of this study was to identify health needs of patients with cholelithiasis undergoing laparoscopic cholecystectomy.

\section{Patients and Methods}

This study was conducted at the Hepato-biliary Surgical Department of Alexandria Main University Hospital. A Convenient sample of 100 adult patients with cholelithiasis who underwent laparoscopic cholecystectomy and meeting the following criteria: 
Post-operative preventive health behaviors: Two questions about preventive health behavior as early ambulation and the time to start it, change the position, leg exercise, breathing exercise and wearing elastic stocking.

Post-operative Food and fluid intake: It included two questions related to the time of starting oral fluids, time of oral feeding, and the suitable type of food to start with after surgery.

Post-operative medications: It included one question that was structured to assess patient's knowledge related to postoperative required medications actions.

2- Post-operative drains and catheter: It included seven questions that structured to assess patient's knowledge related to:

$\square$ Types of drains and catheters as wound drain and foley's urethral catheter.

$\square$ Importance of wound drains that remove fluid and blood formation.

$\square$ Care of wound drain as dressing under aseptic technique, keep the drainage system closed, keep the site of wound dry, the tube not kinked, don't sleep on it and check amount and color of drainage output.

Time of removing wound drain.

Importance of foley's catheter as collection and measurement of urine output.

Care of foley's catheter as keeping drainage system closed, keeping urinary bag under level of urinary bladder, holding beside patient thigh, perineal care, increase fluid intake, observation of amount and color of urine output and not to kink the tube.

$\square$ Time of removing foley's urinary catheter.

3- Post operative complications: It included two questions to assess patient's knowledge related to:

Complications from long period of immobility as muscle weakness, dizziness, breathing disorder, DVT, urinary retention, pressure sore and kidney stones

Complications related to laparoscopy as bile duct injures, clip displacement, bile leakage, hepatic bleeding and infection of abdominal cavity (peritonitis).

4- Self-care following discharge: It included eight questions to assess patient knowledge related to:

Post-operative pain controlling as splinting stomach by placing pillow over abdomen before coughing, distraction by focus on other activities, listening to music, playing games or other engaging activities, guided imagery, pursed lip breathing and taking of prescribed analgesia.

Type of therapeutic diet after discharge as reduced fatty diet, increase fluid $2.5: 3 \mathrm{~L} /$ day, increase proteins, and vitamins.

Care of wound after discharge as keeping wound clean and dry, following wound dressing schedule, if there was bleeding from the wound and checking the wound daily for any signs of infection (redness, pain, swelling, abnormal discharge).

Time of return to activity of daily living.

Calling or visiting the physician when there was symptoms as a sudden pain at the site of surgery, fever, GIT bleeding, increase drainage from incision, delaying of bowel movement for three day and severe calf muscle pain.
Post-operative follow up visits.
D- Preferred source of knowledge, advices and preferred methods of learning.

This item was composed of three questions with fixed alternatives. It was used to assess patient preferred source of knowledge as doctors, nurses, relatives, other patients, media and preferred methods of knowledge \& advices as written, oral, photos.

\section{Scoring system}

A score of two were given to each correct answer, one for incomplete answer and zero for incorrect or not know. A total score of each area was calculated and classified as the following:

Scoring of less than $50 \%$ considered as poor.

Scoring of $50 \%$ to $64 \%$ considered as fair.

$\square$ Scoring of more than or equal $65 \%$ considered as good. 


\section{2-Method}

The study was accomplished as follows:

\section{1- Written approval:}

Official approval to carry out the study was obtained from the hospital responsible authorities at the previously mentioned research settings to obtain their permission to collect necessary data. An official permission was obtained from the directors and head of the departments of the selected hospital setting after explanation the aim of the study.

\section{2- Development of the study tool:}

The study tool was developed by the researcher after extensive reviewing of relevant literature. The content of constructed tool was revised by a jury of 5 experts in the field of Medical Surgical Nursing Department of the Faculty of Nursing at Alexandria University to test content validity, completeness, and clarity of items. Comments and suggestions of jury were considered and the tool was modified accordingly.

3- Section 3 from part 2 in the developed tool was used for patients undergoing surgery.

\section{4- Reliability:}

The reliability of the developed tool was tested by using Alpha Cronbach's statistical test. The tool for the study was applied to fifteen patients. Reliability coefficient value was 0.8 , which is acceptable.

\section{5- A pilot study:}

A pilot study was conducted on fifteen patients to test clarity, feasibility, and applicability of the study tool, and then necessary modifications were done. Patients included in the pilot study were excluded from the study.

\section{6- Data collection:}

After securing the administrative approval, the data collection was started.

After securing the administrative approval and the final draft of the structured tool that was used to collect data in order to achieve the objective of this study, the data were collected by researcher for each patient using individualized interview.

The interview ranged from 30-45 minutes on individual session.

Data were obtained in morning and afternoon shift.

The body mass index (BMI); an index calculated by a ratio of weight in kilograms to height in square meters and used as a measure of obesity. It was then calculated using the following equation: $\mathrm{BMI}=$ weight $(\mathrm{kg}) /$ height $\left(\mathrm{m}^{2}\right)$. Parameters have been established to delineate underweight, normal weight and overweight. Body mass index categories: < 18 underweight, 18.5 to $<25$ desirable or normal weights, 25 to $<$ 30 overweight, 30 to 40 obese and over 40 considered severely obese.

\section{7- Ethical considerations:}

- Written informed consent was obtained from patients participating in the study.

- Confidentiality of data and patient had the right to withdraw at any time in the study and this was emphasized to subjects of the study.

- The anonymity and Privacy of patients were ascertained. The study was approved by the Ethics Board of Alexandria University.

\section{8- Statistical analysis:}

Data analysis was carried out using the Statistical Package of Social Sciences (SPSS, ver18). Data were coded, entered and code checked before analysis. For qualitative variables, data were presented using numbers and percentage from total. On the other hand, mean and standard deviation were used to present the quantitative variable (age).

\section{Results}


Table (1): Socio demographic criteria of the studied patients

\begin{tabular}{|c|c|c|}
\hline Socio demographic characteristics & Frequency $n=100$ & $\%$ \\
\hline \multicolumn{3}{|l|}{ Gender } \\
\hline$\square \quad$ Male & 36 & 36.0 \\
\hline$\square \quad$ Female & 64 & 64.0 \\
\hline \multicolumn{3}{|l|}{ Age } \\
\hline$\square \quad 20<30$ & 11 & 11.0 \\
\hline$\square \quad 30<40$ & 42 & 42.0 \\
\hline \begin{tabular}{|l|}
$\quad 40-50$ \\
\end{tabular} & 47 & 47.0 \\
\hline \multicolumn{3}{|l|}{ Marital Status } \\
\hline \begin{tabular}{|l}
$\quad$ Single \\
$\square$
\end{tabular} & 3 & 3.0 \\
\hline$\quad$ Married & 79 & 79.0 \\
\hline$\square \quad$ Divorced & 7 & 7.0 \\
\hline$\square \quad$ Widow & 11 & 11.0 \\
\hline \multicolumn{3}{|l|}{ Residence } \\
\hline \begin{tabular}{|l|}
$\quad$ Urban \\
\end{tabular} & 29 & 29.0 \\
\hline \begin{tabular}{|l|}
$\quad$ Rural \\
\end{tabular} & 71 & 71.0 \\
\hline \multicolumn{3}{|l|}{ Monthly income } \\
\hline \begin{tabular}{|l}
$\quad$ Enough \\
\end{tabular} & 4 & 4.0 \\
\hline not enough & 96 & 96.0 \\
\hline
\end{tabular}

Regarding gender, it was found that $64 \%$ of the studied patients were females. In relation to age, $47 \%$ of the studied patients were in the age group (40-50) years old. In addition, 79\% of the studied patients were married, and $71 \%$ lived in rural area. Moreover, it was found that $96 \%$ of the studied patients had not sufficient monthly income to fulfill the daily requirements as shown in table (1)

Table (2): The distribution of the studied patients according to disease history

\begin{tabular}{|c|c|c|}
\hline Disease history & Frequency $n=100$ & $\%$ \\
\hline \multicolumn{3}{|l|}{ How did the patient know of having cholelithiasis } \\
\hline$\square \quad$ At onset of symptoms are increased & 40 & 40.0 \\
\hline$\square \quad$ When the severity of symptom increased & 37 & 37.0 \\
\hline$\square \quad$ Accidentally during a follow-up with the doctor & 23 & 23.0 \\
\hline \multicolumn{3}{|l|}{ Duration of illness } \\
\hline$\square \quad$ Less than 3 months & 49 & 49.0 \\
\hline$\square \quad 3-6$ months & 44 & 44.0 \\
\hline$\square \quad$ More than 6 months & 7 & 7.0 \\
\hline \multicolumn{3}{|l|}{ The symptoms complained as a result of cholelithiasis } \\
\hline$\square \quad$ Right hypochondriac Pain & 21 & 21.0 \\
\hline GIT disturbances & 3 & 3.0 \\
\hline$\square \quad$ Dyspepsia & 6 & 6.0 \\
\hline$\square \quad$ Right hypochondriac Pain, dyspepsia & 46 & 46.0 \\
\hline$\square \quad$ Jaundice & 2 & 2.0 \\
\hline $\begin{array}{ll}\quad \text { Fever } \\
\end{array}$ & 22 & 22.0 \\
\hline \multicolumn{3}{|l|}{ Feeling better with treatment? } \\
\hline Yes & 1 & 1.0 \\
\hline$\square \quad$ No & 51 & 51.0 \\
\hline$\square \quad$ Sometimes & 48 & 48.0 \\
\hline
\end{tabular}


This table showed that $40 \%$ of the studied patients were diagnosed at the onset of disease. It was found that $49 \%$ had less than three months duration of cholelithiasis disease. Regarding symptoms related to cholelithiasis, it was observed that $46 \%$ suffered from right hypochondrial pain and dyspepsia.

Table (3): The percentage distribution of the studied patients according to their knowledge regarding to health needs of pre-operative preparation

\begin{tabular}{|c|c|c|c|c|c|c|}
\hline Health needs of preoperative preparation $(n=100)$ & Incor & & Corr & incomplete & Correct & mplete \\
\hline & $\mathrm{N}$ & $\%$ & $\mathrm{~N}$ & $\%$ & $\mathrm{~N}$ & $\%$ \\
\hline The types of surgical treatment & 40 & 40.0 & 22 & 22.0 & 38 & 38.0 \\
\hline $\begin{array}{l}\text { The important preparations and } \\
\text { instructions necessarv before surgerv }\end{array}$ & 54 & 54.0 & 44 & 44.0 & 2 & 2.0 \\
\hline The importance of breathing exercises & 81 & 81.0 & 10 & 10.0 & 9 & 9.0 \\
\hline The procedure of breathing exercises & 94 & 94.0 & 4 & 4.0 & 2 & 2.0 \\
\hline The importance of limb exercises & 70 & 70.0 & 25 & 25.0 & 5 & 5.0 \\
\hline Procedure of post-operative leg exercises & 66 & 66.0 & 30 & 30.0 & 4 & 4.0 \\
\hline
\end{tabular}

Regarding type of surgery to be performed, table (3) showed that $40 \%$ of studied patients did not know or gave a wrong answer about the type of surgery. In relation to pre-operative preparation and teaching before surgery, 54\% of studied patients did not have knowledge about pre-operative preparation before surgery. Concerning importance of post-operative exercise, it was observed that all studied patients did not know the importance of breathing exercise and its technique. Regarding importance of post-operative limb exercise, it was found that $70 \%$ of the studied patients gave wrong answer or did not know. Considering post-operative leg, forearm exercises techniques, it was obvious that $66 \%$ of the studied patients gave wrong answer or didn't know.

Table (4): The percentage distribution of studied patients according to their knowledge regarding health needs of post-operative care

\begin{tabular}{|c|c|c|c|c|c|c|}
\hline \multirow{2}{*}{$\begin{array}{l}\text { Health needs of postoperative care } \\
(n=100)\end{array}$} & \multicolumn{2}{|c|}{ Incorrect } & \multicolumn{2}{|c|}{ Correct incomplete } & \multicolumn{2}{|c|}{ Correct complete } \\
\hline & $\mathrm{N}$ & $\%$ & $\mathrm{~N}$ & $\%$ & $\mathrm{~N}$ & $\%$ \\
\hline \multicolumn{7}{|l|}{ 1- postoperative period: } \\
\hline The postoperative preventive health behaviors & 21 & 21.0 & 74 & 74.0 & 5 & 5.0 \\
\hline Time of moving after surgery & 15 & 15.0 & 83 & 83.0 & 2 & 2.0 \\
\hline Time to start eating after surgery & 10 & 10.0 & 77 & 77.0 & 13 & 13.0 \\
\hline Permissible foods after surgery & 15 & 15.0 & 80 & 80.0 & 5 & 5.0 \\
\hline Drugs that can be taken after the operation? & 27 & 27.0 & 70 & 70.0 & 3 & 3.0 \\
\hline \multicolumn{7}{|l|}{ 2- postoperative drains and catheter care } \\
\hline Know post-operative drain and catheters attached & 69 & 69.0 & 13 & 13.0 & 18 & 18.0 \\
\hline Know the importance of Foley urethral catheter & 77 & 77.0 & 6 & 6.0 & 17 & 17.0 \\
\hline Care of Foley urethral catheter & 70 & 70.0 & 26 & 26.0 & 4 & 4.0 \\
\hline Time of Foley urethral catheter removal & 90 & 90.0 & & & 10 & 10.0 \\
\hline The importance of wound drain & 67 & 67.0 & 12 & 12.0 & 21 & 21.0 \\
\hline Care of wound drain & 48 & 48.0 & 40 & 40.0 & 12 & 12.0 \\
\hline Time of wound drain removal & 90 & 90.0 & 7 & 7.0 & 3 & 3.0 \\
\hline \multicolumn{7}{|l|}{ 3- postoperative complications: } \\
\hline Complications of long periods of immobility & 16 & 16.0 & 83 & 83.0 & 1 & 1.0 \\
\hline Complications of laparoscopy & 84 & 84.0 & 14 & 14.0 & 2 & 2.0 \\
\hline
\end{tabular}

Regarding the preventive health behaviors to prevent complications that include (early mobility, change position frequently, breathing exercise, leg exercise and wearing elastic stocking), it was observed that $74 \%$ of the studied patients reported correct incomplete answer. In 
relation to start mobility after surgery, it was found that $83 \%$ had correct incomplete answer. Concerning the time to start eating after surgery, most of the studied patients knew correct and incomplete answer. $80 \%$ of the studied patients gave correct incomplete knowledge about the food intake allowed after surgery. In relation to post-operative drug, it was observed that $70 \%$ of studied patients gave correct incomplete answer. As regards knowledge about the postoperative drains and catheter, it was obvious that no studied patients knew about the attached drain and catheter after Surgery. In relation to the importance of Foley's catheter, it was observed that $77 \%$ of the studied patients gave wrong answer or did not know. Concerning the care and the time of removal of Foley's catheter, the majority of studied patients gave wrong answer or did not know. Finally, table (4) revealed that $83 \%$ of studied patients had correct incomplete answer about complication of surgery from long period of immobility. On the other hand, majority of them gave wrong answer or did not know the answer about the complication of laparoscopy.

Table (5): The percentage distribution of the studied patients according to their knowledge regarding self-care following discharge.

\begin{tabular}{|c|c|c|c|c|c|c|}
\hline \multirow[t]{2}{*}{ Self-care following discharge $(n=100)$} & \multicolumn{2}{|c|}{ Incorrect } & \multicolumn{4}{|c|}{ Correct incomplete Correct complete } \\
\hline & $\mathrm{N}$ & $\%$ & $\mathrm{~N}$ & $\%$ & $\mathrm{~N}$ & $\%$ \\
\hline Control of post-operative pain & 24 & 24.0 & & & 76 & 76.5 \\
\hline Therapeutic diet after discharge & 49 & 49.0 & & & 51 & 51.0 \\
\hline Care of the wound after discharge & 14 & 14.0 & 71 & 71.0 & 15 & 15.0 \\
\hline Ability to return to ADL & 93 & 93.0 & 2 & 2.0 & 5 & 5.0 \\
\hline Ability to return to work & 93 & 93.0 & 2 & 2.0 & 5 & 5.0 \\
\hline The situations that require contact of the doctor & 28 & 28.0 & 59 & 59.0 & 13 & 13.0 \\
\hline Return to regular follow up & 93 & 93.0 & 4 & 4.0 & 3 & 3.0 \\
\hline Follow-up visits after the operation & 33 & 33.0 & 51 & 51.0 & 16 & 16.0 \\
\hline
\end{tabular}

Regarding to control of post-operative pain, $67.5 \%$ of the studied patients gave correct complete answer. Concerning the therapeutic diet after discharge, $51 \%$ reported complete correct answer. In addition, table (5) showed that $93 \%$ did not know or informed wrong answer about the ability to return to ADL and to the work. Regarding the situation that requires contact of the doctor, 59\% of the studied patients reported correct incomplete answer. In relation to return to regular follow up, it was obvious that $93 \%$ did not know or informed wrong answer. Finally, this table revealed that $51 \%$ of studied patients had correct incomplete answer about follow- up visits after operation.

Table (6): The percentage distribution of the studied patients according to source of knowledge and advice

\begin{tabular}{|c|c|c|c|c|}
\hline \multirow[t]{2}{*}{ Source of knowledge and advices $n=100$} & \multicolumn{2}{|c|}{ No } & \multicolumn{2}{|r|}{ Yes } \\
\hline & $\mathbf{N}$ & $\%$ & $\mathbf{N}$ & $\%$ \\
\hline The doctor & 1 & 1.0 & 99 & 99.0 \\
\hline Nurse & 14 & 14.0 & 86 & 86.0 \\
\hline Relatives & 47 & 47.0 & 53 & 53.0 \\
\hline Patients & 68 & 68.0 & 32 & 32.0 \\
\hline Media & 24 & 24.0 & 76 & 76.0 \\
\hline \multicolumn{5}{|l|}{ Preferred source of information } \\
\hline The doctor & 3 & 3.0 & 97 & 97.0 \\
\hline Nurse & 15 & 15.0 & 85 & 85.0 \\
\hline Relatives & 0 & 0.00 & 100 & 100.0 \\
\hline Patients & 100 & 100.0 & 0 & 0.0 \\
\hline Media & 98 & 98.0 & 2 & 2.0 \\
\hline \multicolumn{5}{|l|}{ Preferred health education method } \\
\hline Written & 92 & 92.0 & 8 & 8.0 \\
\hline Oral & 10 & 10.0 & 90 & 90.0 \\
\hline Written, oral & 91 & 91.0 & 9 & 9.0 \\
\hline Photos and graphics & 86 & 86.0 & 14 & 14.0 \\
\hline
\end{tabular}


Health Needs of Patients with Cholelithiasis Undergoing Laparoscopic Cholecystectomy

This table revealed that physicians were the main source of advice and knowledge for $99 \%$ of patients. In addition, they were the main preferred source to give advice or knowledge for $97 \%$ of patients and $90 \%$ preferred oral methods.

Table (7): The relation between knowledge level and characteristics of the studied patients

\begin{tabular}{|c|c|c|c|c|c|c|c|c|}
\hline \multirow{3}{*}{$\begin{array}{c}\text { Patients' } \\
\text { Characteristic }\end{array}$} & \multicolumn{6}{|c|}{ Knowledge level } & \multirow[t]{3}{*}{ Total } & \multirow[t]{3}{*}{ Monte Carlo test } \\
\hline & \multicolumn{2}{|c|}{ Poor $n=88$} & \multicolumn{2}{|c|}{ Fair $n=8$} & \multicolumn{2}{|c|}{ Good $n=4$} & & \\
\hline & $\mathbf{N}$ & $\%$ & n & $\%$ & $\mathbf{N}$ & $\%$ & & \\
\hline \multicolumn{9}{|l|}{ Age (years) } \\
\hline $20<30$ & 9 & 81.8 & 2 & 18.2 & 0 & 0.0 & $11(100 \%)$ & \multirow{3}{*}{$\begin{array}{l}X^{2}=4.6 \\
P=0.33\end{array}$} \\
\hline $30<40$ & 35 & 83.3 & 4 & 9.5 & 3 & 7.1 & $42(100 \%)$ & \\
\hline $40<50$ & 44 & 93.6 & 2 & 4.3 & 1 & 2.1 & $47(100 \%)$ & \\
\hline \multicolumn{9}{|l|}{ Sex } \\
\hline Male & 32 & 88.9 & 3 & 8.3 & 1 & 2.8 & $36(100 \%)$ & \multirow{2}{*}{$\begin{array}{l}\mathrm{X}^{2}=0.223 \\
\mathrm{P}=1.0\end{array}$} \\
\hline Female & 56 & 87.5 & 5 & 7.8 & 3 & 4.7 & $64(100 \%)$ & \\
\hline \multicolumn{9}{|l|}{ Marital status } \\
\hline Single & 3 & 100.0 & 0 & 0.0 & 0 & 0.0 & $3(100 \%)$ & \multirow{4}{*}{$\begin{array}{l}X^{2}=4.41 \\
P=0.52\end{array}$} \\
\hline Married & 69 & 87.3 & 7 & 8.9 & 3 & 3.8 & $79(100 \%)$ & \\
\hline Divorced & 5 & 71.4 & 1 & 14.3 & 1 & 14.3 & $7(100 \%)$ & \\
\hline Widow & 11 & 100.0 & 0 & 0.0 & 0 & 0.0 & $11(100 \%)$ & \\
\hline \multicolumn{9}{|l|}{ Residence area } \\
\hline Urban & 18 & 62.1 & 7 & 24.1 & 4 & 13.8 & $29(100 \%)$ & \multirow{2}{*}{$\begin{array}{l}\mathrm{X}^{2}=26.2 \\
\mathrm{P}=0.00 *\end{array}$} \\
\hline Rural & 70 & 98.6 & 1 & 1.4 & 0 & 0.0 & $71(100 \%)$ & \\
\hline \multicolumn{9}{|l|}{ Income } \\
\hline \begin{tabular}{|l|} 
Enough \\
\end{tabular} & 0 & 0.0 & 1 & 25.0 & 3 & 75.0 & $4(100 \%)$ & \multirow{2}{*}{$\begin{array}{l}X^{2}=57.7 \\
P=0.00 *\end{array}$} \\
\hline Not enough & 88 & 91.7 & 7 & 7.3 & 1 & 1.0 & $96(100 \%)$ & \\
\hline
\end{tabular}

*statistically significant at $\mathrm{P} \leq 0.05$

This table revealed that there was statistically significant positive correlation between patients' knowledge level and residence area $(\mathrm{p}=0.00)$ and income $(\mathrm{p}=0.00)$.

Table (8): The relation between knowledge level and source of knowledge among the studied patients

\begin{tabular}{|c|c|c|c|c|c|c|c|c|}
\hline \multirow{4}{*}{$\begin{array}{c}\text { Source of knowledge } \\
\text { and advices }\end{array}$} & \multicolumn{6}{|c|}{ Patients level of knowledge } & \multirow[t]{4}{*}{ Total } & \multirow[t]{4}{*}{ Monte Carlo test } \\
\hline & \multirow{2}{*}{\multicolumn{2}{|c|}{$\begin{array}{l}\text { Poor } \\
n=88\end{array}$}} & \multirow{2}{*}{\multicolumn{2}{|c|}{$\begin{array}{c}\text { Fair } \\
n=8\end{array}$}} & \multirow{2}{*}{\multicolumn{2}{|c|}{$\begin{array}{c}\text { Good } \\
n=4\end{array}$}} & & \\
\hline & & & & & & & & \\
\hline & $\mathrm{n}$ & $\%$ & $\mathrm{n}$ & $\%$ & $\mathrm{~N}$ & $\%$ & & \\
\hline \multicolumn{9}{|l|}{ Doctor } \\
\hline No & 1 & 100.0 & 0 & 0.0 & 0 & 0.0 & $1(100 \%)$ & \multirow{2}{*}{$x^{2}=0.14$} \\
\hline Yes & 87 & 87.9 & 8 & 8.1 & 4 & 4.0 & $99(100 \%)$ & \\
\hline \multicolumn{9}{|l|}{ Nurse } \\
\hline No & 10 & 71.4 & 0 & 0.0 & 4 & 28.6 & $14(100 \%)$ & \multirow{2}{*}{$x^{2}=26.4$} \\
\hline Yes & 78 & 90.7 & 8 & 9.3 & 0 & 0.0 & $86(100 \%)$ & \\
\hline \multicolumn{9}{|l|}{ Relatives } \\
\hline No & 37 & 78.4 & 7 & 14.9 & 3 & 6.4 & $47(100 \%)$ & \multirow{2}{*}{$x^{2}=7.4$} \\
\hline Yes & 51 & 96.2 & 1 & 1.9 & 1 & 1.9 & $53(100 \%)$ & \\
\hline \multicolumn{9}{|l|}{ Patients } \\
\hline No & 57 & 83.8 & 7 & 10.3 & 4 & 5.9 & $68(100 \%)$ & \multirow{2}{*}{$x^{2}=3.7$} \\
\hline Yes & 31 & 96.9 & 1 & 3.1 & 0 & 0.0 & $32(100 \%)$ & \\
\hline \multicolumn{9}{|l|}{ Media } \\
\hline No & 21 & 87.5 & 0 & 0.0 & 3 & 12.5 & $24(100 \%)$ & \multirow{2}{*}{$x^{2}=8.2$} \\
\hline Yes & 67 & 88.2 & 8 & 10.5 & 1 & 1.3 & $76(100 \%)$ & \\
\hline
\end{tabular}

*statistically significant at $\mathrm{P} \leq 0.05$ 
Table (8) revealed that there was a statistically significant positive correlation between patients' knowledge level and nurse advices $(\mathrm{p}=0.00)$, media $(\mathrm{p}=0.02)$ and relatives $(\mathrm{p} 0.02)$. On the other hand, it was noticed that there was no significant correlation between patients' knowledge level from the doctors and patients. It was revealed in table (9) that there was a statistically significant positive correlation between patients' knowledge level and nurses as preferred source of knowledge and advices $(\mathrm{p}=$ 0.00 ). In addition, there was a statistically significant positive correlation between patients' knowledge level and written \& oral method of health education as preferred method $(\mathrm{p}=0.01)$.

Table (9): The relation between knowledge level and preferred source among the studied patients

\begin{tabular}{|c|c|c|c|c|c|c|c|c|}
\hline \multirow{3}{*}{$\begin{array}{c}\text { Preferred Source of } \\
\text { knowledge }\end{array}$} & \multicolumn{6}{|c|}{ Patients level of knowledge } & \multirow[t]{3}{*}{ Total } & \multirow[t]{3}{*}{ Monte Carlo test } \\
\hline & \multicolumn{2}{|l|}{$\begin{array}{l}\text { Poor } \\
\text { n=88 }\end{array}$} & \multicolumn{2}{|c|}{$\begin{array}{l}\text { Fair } \\
\mathrm{n}=8\end{array}$} & \multicolumn{2}{|c|}{$\begin{array}{c}\text { Good } \\
n=4\end{array}$} & & \\
\hline & $\mathrm{n}$ & $\%$ & $\mathrm{~N}$ & $\%$ & $\mathrm{~N}$ & $\%$ & & \\
\hline \multicolumn{9}{|l|}{ Doctor } \\
\hline No & 3 & 100.0 & 0 & 0.0 & 0 & 0.0 & $3(100 \%)$ & $x^{2}=$ \\
\hline Yes & 85 & 87.6 & 8 & 8.2 & 4 & 4.1 & $97(100 \%)$ & $\begin{array}{l}\lambda=0 . \\
P=1.0\end{array}$ \\
\hline \multicolumn{9}{|l|}{ Nurse } \\
\hline No & 10 & 66.7 & 1 & 6.7 & 4 & 26.7 & $15(100 \%)$ & $\mathrm{y}^{2}-226$ \\
\hline Yes & 78 & 91.8 & 7 & 8.2 & 0 & 0.0 & $85(100 \%)$ & $\mathrm{P}=0.00^{*}$ \\
\hline \multicolumn{9}{|l|}{ Relatives } \\
\hline No & 88 & 88.0 & 8 & 8.0 & 4 & 4.0 & $100(100 \%)$ & \\
\hline Yes & 0 & 0.0 & 0 & 0.0 & 0 & 0.0 & $0(100 \%)$ & \\
\hline \multicolumn{9}{|l|}{ Patients } \\
\hline No & 88 & 88.0 & 8 & 8.0 & 4 & 4.0 & $100(100 \%)$ & \\
\hline Yes & 0 & 0.0 & 0 & 0.0 & 0 & 0.0 & $0(100 \%)$ & \\
\hline \multicolumn{9}{|l|}{ Media } \\
\hline No & 87 & 88.8 & 7 & 7.1 & 4 & 4.1 & $98(100 \%)$ & $x^{2}=49$ \\
\hline Yes & 1 & 50.0 & 1 & 50.0 & 0 & 0.0 & $2(100 \%)$ & $\mathrm{P}=0.09$ \\
\hline \multicolumn{9}{|c|}{ Preferred method of education } \\
\hline \multicolumn{9}{|l|}{ Written } \\
\hline No & 81 & 88.0 & 7 & 7.6 & 4 & 4.3 & $92(100 \%)$ & $x^{2}=057$ \\
\hline Yes & 7 & 87.5 & 1 & 12.5 & 0 & 0.0 & $(100 \%)$ & $\mathrm{P}=1.0$ \\
\hline \multicolumn{9}{|l|}{ Oral } \\
\hline No & 8 & 80.0 & 2 & 20.0 & 0 & 0.0 & $10(100 \%)$ & $x^{2}=25$ \\
\hline Yes & 80 & 88.9 & 6 & 6.7 & 4 & 4.4 & $90(100 \%)$ & $\mathrm{P}=0.23$ \\
\hline \multicolumn{9}{|l|}{ Oral \& Written } \\
\hline No & 83 & 91.2 & 4 & 4.4 & 4 & 4.4 & $91(100 \%)$ & $x^{2}=178$ \\
\hline Yes & 5 & 55.6 & 4 & 44.4 & 0 & 0.0 & $9(100 \%)$ & $\mathrm{P}=0.01^{*}$ \\
\hline \multicolumn{9}{|c|}{ Photographs and graphics } \\
\hline No & 77 & 89.5 & 5 & 5.8 & 4 & 4.7 & $86(100 \%)$ & $x^{2}=45$ \\
\hline Yes & 11 & 78.6 & 3 & 21.4 & 0 & 0.0 & $14(100 \%)$ & $\mathrm{P}=0.17$ \\
\hline
\end{tabular}

*statistically significant at $\mathrm{P} \leq 0.05$ 


\section{Discussion}

The findings of the present study indicated that the majority of the studied patients had poor knowledge level regarding gallstones nature and its management. Therefore, those patients must have health needs toward risk factors of disease, treatment modalities available, preoperative and post-operative care, complications and self-care following discharge after surgery. Most of the studied patients reported that physicians and the nurses were the preferred source of knowledge. In addition, there were high statistically significant differences that were found between patients' knowledge level and age and educational level, as well as positive relation was found between patients' knowledge level and nurse advices.

Regarding age, the results of the present study revealed that more than half of the studied patients were in the age group between 30-50 years old. This finding agreed with Nidoni ${ }^{(4)}$ as he found that the incidence of cholelithiasis increases sharply with age which indicates that aging is one of the strongest and most prevalent risk factor for cholelithiasis. This was attributed to that as age increased, the incidence of metabolic syndrome is increased, which is closely related to the occurrence of gallstones. This finding also lined with Panpimanmas et al. ${ }^{(5)}$ who mentioned that high prevalence of gallstones occur with progression of age.

Concerning gender, this study showed that, more than half of the studied patients were females. This finding is supported by Khalaf $\boldsymbol{e t}$ al. ${ }^{\left({ }^{6}\right)}$ who stated that the females have higher risk of cholelithiasis than males. Additionally, this result agreed with Bass et al. ${ }^{(7)}$ and Hung et $\boldsymbol{a l} .{ }^{(8)}$ who found that most of their studied patients were females, who had a higher prevalence of gallstones, which could be due to menopause, as a risk factor of gallstones in women $>50$ years old. They added that estrogen levels increase the saturation of cholesterol in bile and in turn enhances the formation of gallstones. Also, similar studies by Kim et al. ${ }^{\left({ }^{(9)}\right.}$ reported the same results.

As regards educational level, this study showed that, most of the patients were basic and secondary educated. This finding is supported by Alishi et $\boldsymbol{a l} .{ }^{(10)}$ as they reported that most of their studied patients for cholelithiasis were educated. However, it was inconsistent with
Leotine (11) who reported that most of participants were illiterates.

In relation to the area of residence, the present study showed that the highest percentage of patients came from rural areas. This might be related to lack of education, poor knowledge, poor sanitation and insufficient income with high risks of gallstones. This agreed with Naeem et al. ${ }^{(12)}$ who found that the majority of the studied patients lived in rural area where health care facilities were not available or were very primitive.

Regarding marital status, it was noticed that the majority of the studied patients were married. These findings revealed association between marital status and gallstones because multi paraous women are risky for gallstones. This is supported with the study of Channa et al. ${ }^{(13)}$ who demonstrated that in females, the marriage at earlier age was positively associated with having gallstone diseases and the early marriages can lead to longer fertility periods and higher parity rates. Therefore, the female sex hormones due to fertilities can play excusive role for gallstone.

In relation to family income, it was noticed that the majority of the studied patients had insufficient income to fulfill their daily requirement. This might be related to increased poverty and unemployment in Egypt especially in rural areas. These findings agreed with the study of Lu et al. ${ }^{(14)}$ and Hung et al. ${ }^{(8)}$ who reported association between cholelithiasis and low economic state. Therefore, the majority of the studied patients were under the umbrella of University free hospital.

Regarding medical history of cholelithiasis, this finding showed that most of patients with cholelithiasis discovered symptoms of disease from 3-6 months when the severity of symptoms increased. This respected with the result of Mertens et al. ${ }^{(15)}$ who reported that patients had complained of cholelithiasis symptoms such as biliary pain, nausea, vomiting and dyspepsia less than 6 month. However, the study of Tornqvist (16) contradicts this finding and reported that patients with cholelithiasis had not any experience of symptoms and considered an incidental finding discovered accidently during abdominal ultrasound. Moreover, the 
study mentioned that the most common symptoms of cholelithiasis were right hypochondrial pain, dyspepsia and fever. This result is supported with the study of Sharada et al. ${ }^{(17)}$.

In relation to knowledge of the studied patients regarding to pre- operative preparation, the current study revealed that most of studied patients had poor knowledge about preoperative preparation as fasting, skin care ,type of surgery and type of anesthesia, breathing exercise, duration of surgery and importance of pre- operative preparation. This finding agreed with lilian ${ }^{(18)}$ who informed that any patient who is undergoing surgical procedure in general and in particular should be fully educated especially about surgical procedure for its benefits and risks in addition to routine pre- and post-operation. In addition, this finding is supported by Raj et al. ${ }^{(19)}$ who reported that the surgical patients need teaching and education about breathing exercise prior to surgery and instructional demonstration for it. In addition, Sun et $\boldsymbol{a l} .{ }^{(20)}$ stated that most of participants had lack of proper information regarding pre-operative preparation such as information of patients about type of surgery and its benefits and risks and prevention of post-operative complications. This is a barrier against effective nurse-patient relationship because the nursing staff is so busy due to the weight of work. However, this finding contradicts El-nasser et al. ${ }^{(21)}$ who reported that the majority of studied patients were highly satisfied with the preoperative regarding type of anesthesia, type of surgery, operating room orientation, duration of operation and fasting hours before surgery and this was related to good staff-patient therapeutic relationship for providing adequate information about preparation of pre-operative care to improve outcome of surgery.

Concerning post-operative patient exercise and the time for starting mobility after surgery, the current study revealed that more than half of studied patients had poor health-related knowledge about importance of post-operative breathing and leg exercise technique. This might rationalize by that the majority of them ignored importance and techniques of exercise from health care provider in pre-operative plan of care. Moreover, the presence of pain may limit the ability of the patients to practice any type of exercise post operatively. So, Liddle (22) emphasized about the importance of breathing and leg exercise post operatively. In addition, the current study showed that most of studied patients had unsatisfactory level of knowledge about the time for starting mobility after surgery. Additionally, this finding agreed with Chatterley ${ }^{(23)}$ who stated that patients need to understand the time and the benefits of early mobilization for positive impact on functional outcomes and decrease post-operative complication. So, the nurse should encourage educational program that may increase prioritization of early mobilization in nursing care of post-operative patients.

Regarding knowledge of post-operative complications and its preventive measures, the current study revealed that the majority of studied patients had incomplete answer about preventive measures for post-operative complications that included (early mobility, change position frequently and breathing exercise). This result may be referred to low educational level of the most of studied patients which resulted in lack of knowledge about importance of preventive measures for postoperative complications. The result of the present study is in harmony with Shaw ${ }^{(24)}$ who mentioned that the main responsibility of the nurse is provision of information and instruction during preoperative phase not only to decrease stress and anxiety but to maintain faster recovery and prevent post-operative complication. This occurs by following instructions such as early mobility after surgery, breathing and cough exercise, instruction related to infection $\mathrm{pre} v \mathrm{e} \mathrm{ti}$ ve measure, wound care and other instructions. This finding is in the line with Herzog ${ }^{(25)}$ who informed that the majority of participants had not satisfactory knowledge regarding post-operative complication such as respiratory, cardiac and bleeding complications.

In relation to post-operative drugs, most of participants had correct and incomplete answer about medication and this might be related to deficit of patient knowledge about the surgery and medication. This reflect the failure of health care providers to provide patients with postoperative medication instruction because of short stay in hospital after surgery for considering laparoscopic cholecystectomy as a day-case surgery and increasing number of patients who are undergoing surgery. This cause lacking of time to nurse for informing 
all patients' post-operative instruction. This agreed with Grossweiler ${ }^{\text {(26) }}$ who reported that with proper education and awareness of expectations and goals of surgical procedure, the patients were empowered with the information provided by the nurse in a variety of areas including instructions of post-operative medication, pain management and follow up during pre-admission phase to improve positive outcome.

Regarding knowledge about the post-operative drains and catheter for its importance and care of it, the current study revealed that high percentage of the studied subjects were lacking knowledge about importance and care of drains and catheter after surgery. This finding is supported by Rosen $\boldsymbol{e t}$ al. ${ }^{(27)}$ who informed that most of participant had lack of knowledge about wound care and wound drain. This occurred due to insufficient of providing information by health care providers about care of wound. In addition to, this finding agreed with Sunhonen et al. ${ }^{(28)}$ who concluded that most of studied patients had lack of knowledge about wound care after discharge because patients received inappropriate and inconsistent information from professionals about care of wound.

Considering post-operative pain controlling, during the current study, we detected that there was high level of health needs toward postoperative pain control. This finding is demonstrated by Shaw ${ }^{(24)}$ who mentioned that most of participants indicated that they had good experience in the control of pain after surgery, while this coming in the contradiction with Alam ${ }^{(31)}$ and Herzog ${ }^{(25)}$ who informed that most of studied patients had lack of information about pain management, wound care, therapeutic diet and post- operative complication. They emphasize on appositive experience with discharge teaching that created an increased satisfaction of care, increased compliance to treatment, acceptance of responsibility of self-care and an easier discharge to home.

Regarding self-care following discharge, the current study detected poor knowledge about self-care following discharge including (therapeutic diet after discharge, time to return to $\mathrm{ADL}$ and the situation that require contact with the doctor). This finding agreed with Brenner et al. ${ }^{(29)}$ who stated that the nurse must inform the patient who are undergoing laparoscopic cholecystectomy about detailed home instructions that include post-operative medication, activity, diet, wound care and the situation that patients should contact with the surgeon if he experienced any of the following post-operative complications such as shortness of breath and increase of redness, swelling or drainage at the site of incision, fever, nausea, vomiting and no bowel movement by two or three days after surgery. Also, Bhagirathee $\mathbf{p}$ (30) reported that the majority of studied patients had lack of knowledge about what to expect concerning recovery such as when the participant return to ordinary life and return to ADL.

In relation to return to regular follow up, it was obvious that most of studied patients had poor knowledge about regular follow up. It might be because most of them were from rural areas as a far place that might they neglected follow up visits. This agreed with Lithnner et al. ${ }^{(31)}$ who informed about the importance of patients' needs for information regarding regular follow up visits and without information the patient were unable to take active part in post-operative care.

In relation to source of knowledge and advice of the studied patients during the present study, we detected that the majority of the studied patients received their knowledge from doctors and nurses. This finding is supported by Stergiopoulou ${ }^{(32)}$ who reported that effective informative sessions is very important by health professionals for adult surgical patients to improve rapid post-operative recovery. While this coming in the contradiction with Elwin ${ }^{(33)}$ who mentioned that patients received information on most aspects related to laparoscopic cholecystectomy by medical practitioner (surgeons, anesthetists and surgical registrar) not by the nurse.

Regarding preferred source of knowledge and advices of the studied patients, the present study revealed that the majority of patients considered the physician and the nurse as their most preferred source of knowledge and advice. This finding is supported by Donoghue et al. ${ }^{(34)}$ who reported that patients want to obtain information related to their health or disease process from health professional team including doctors and nurses.

Regarding preferred method for information, the result of this study showed that the majority 
of the studied patients preferred oral then written methods. This is supported by Lilian ${ }^{(18)}$, Donoghue et al. ${ }^{(34)}$ and Lithnner et al. ${ }^{(31)}$ who reported that verbal and written reports are the main dissemination modalities used by nurse to disseminate information related to perioperative care.

As regards the relationship between patients' knowledge level and their socio demographic characteristics, the present study detected that there was a statistically significant difference between the patients' level of knowledge and their educational level. This finding is supported by Leotine ${ }^{(11)}$ who mentioned that there was a significant correlation between patients' knowledge and educational level. Otherwise, during the present study, we detected that there was no statistically significant difference between the patient's level of knowledge and their gender, sex and their occupation.

As regards the relationship between patients' knowledge level and their relation to preferred source of knowledge and advice, the present study showed that there was a statistically significant relation between the patients' level of knowledge and their preferred source of knowledge as the nurses. This finding is supported by Alam ${ }^{(35)}$ who mentioned that nurses who provide perioperative care must have knowledge of implication of procedure, clinical manifestations of complication and risk factors and identify patients at high risk for adverse outcomes. All these allow the nurse to anticipate the needs of the patients and provide a less stressful post-operative experience. Finally, nurses must provide better information to adult surgical patients. It points out that surgical patients have a specific health needs during the perioperative period and these needs remain stable. However, the findings about the provision of information in important areas to surgical patients were inconsistent. Therefore, more emphasis should be put into evaluating and assessing surgical patients' individual needs. Another important issue is the use of this knowledge in nursing practice. Also, the discussion confirms that information, which is individualized to a certain patient characteristics, has a crucially important role for surgical patients. Information to surgical patients appears to have an empowering effect, enabling them to take more control over their health care, and to comply with medical treatment.

\section{Conclusion}

The current study tried to identify health needs of patients diagnosed with cholelithiasis who were undergoing laparoscopic cholecystectomy. Based on the study findings, it could be concluded that, majority of the studied patients $(88 \%)$ had poor knowledge level. There was no statistically significant relation between sex, age, occupation and health needs. While, there was statistically significant relation between educational level, income, residence area, treatment system and health needs to inform about laparoscopic cholecystectomy. Regarding the source of knowledge, statistically significant relation between health needs and nurse was found. Therefore, increases the demand on the nurse in provision the correct amount of information specific to the three phases of surgery (pre, intra and post-operative) for patients who are undergoing laparoscopic cholecystectomy.

\section{References}

1- Prenner P, Donald D et al. (2015): Postoperative care of patients undergoing same-day laparoscopic cholecystectomy. AORN Journal, 102 (1): $15-17$

2-Guarino MP, Cocca S et al. (2013): Ursodeoxycholic acid therapy in gallbladder disease, a story not yet completed. World $\mathbf{J}$ Gastroenterol., 19(31): 5029-34.

3-Renholm M (2015): Continuity of patient care in day surgery. Department of Nursing Science, Faculty of Medicine, University of Turku, Finland Annales Universitatis Turkulensis, Painosalama Oy, Turku.website

4- Nidoni R, Udachan $T$ P et al. (2015): Predicting difficult laparoscopic cholecystectomy based on clinic radiological assessment. Journal of Clinical and Diagnostic Research, 9 (12): 9-12.

5- Panpimanmas S, Mannee C et al. (2009): Risk factor for gallstone disease in Thai population. Epidemiology Journal, 19 (3): 11612.

6-Khalaf SK (2016): Prevalence and risk factors of asymptomatic gallstone in a sample of population in Barsrah. Iraq Archives of medicine, 8 (8):1-7. 
7-Bass G, Gilani S et al. (2013): Validating the $5 \mathrm{f}_{\mathrm{S}}$ mnemonic for cholelithiasis: Time to include family history. Post Graduate Medicine Journal, 6(89): 638-41

8-Hung S, Liao K et al. (2011): Risk factors associated with symptomatic cholelithiasis in Taiwan: a population -based study. Bmc gastroenterology Journal, (11):111.

9-Kim S, Lee HS et al. (2006): prevalence and risk factors of gallbladder polyp in adults living in Taegu and Gyeongbuk provinces. The Korean Journal of Gastroenterology, (48):3450.

10-Alishi Y, Howaish F et al. (2017): Prevalence and risk factor for gallstone among population in Riyadh City, KSA. The Egyptian Journal of Medicine, 69(5):2384-388.

11-Leontine I (2017): Patient satisfaction with peri- operative care at Oshen Fing Faisal Hospital. Master's Thesis, Dissertations, University of Rwanda .

12-Naeem M, Rahimnajjad N et al. (2012): Assessment of characteristic of patients with cholelithiasis from economically deprived rural Krachi Pakistan .PMC Journal, (5):333-34.

13-Channa N and Khand F (2013): Gallstones and dietary risk factors: an epidemiologic investigation in southern Sindh, Pakistan. RMJ., 38(4):361-365.

14-Lu P, Yang N et al. (2018): Effect of socioeconomic inequalities on cholelithiasis outcome :a 10 years population -based analysis .International Journal for equity health, 36(8):17-22

15-Mertens M, Roukema J et al. (2010): Risk assessment of cholelithiasis: is cholecystectomy to be preferred? Journal Gastrointestinal Surgery, (14)6:1271-79.

16-Tornqvist B (2013): Iatrogenic bile duct injury during cholecyctectomy. Master's Thesis, Dissertations, Karolinska Institutet Swedan.

17-Sharada B and Srinivas D (2017): Clinical study of cholelithiasis. International Journal of Scientific Study, 5(3):210-14.
18-Lilian A (2016): Pre-operative patient assessment practices .American Journal Of Nursing Science, 5(5):185-190.

19-Raj A and Kathyayani BV (2016): Preoperative breathing exercise using instructional demonstration in preventing post-operative pulmonary complications for patients undergoing abdominal surgery. Mpi J of nurs Health Sci., 2(1):16-20.

20-Sun H (2017): patients' perception of the nurse patient relationship in post-operative care. Master's Thesis, Dissertations, JAMK University of applied sciences.

21- El-nasser G and Mohamed N (2013): Patient satisfaction with preoperative care and its relationship with patient charcteristics. Med J Cairo Univ., 81(2):1-10.

22-Liddle C (2012): Preparing patients to undergo surgery. Nurs Times Journal, 108(48):12-13.

23-Chatterley L (2017): Improving nurse knowledge and attitude of mobilization of the post-operative patient. digitalcommons.ric.edu/etd/188/

24-Shawa E (2012): Patients perception regarding nursing care in the general surgical wards at Kenyatta National Hospital. Master Thesis. School of Nursing Science: University of Nairobi.

25-Herzog SA (2010): Briatric patients knowledge of post-operative complication and life styles changes. Doctoral dissertation, Montana State University-Bozeman, College of Nursing.

26-Grossweiler H (2012): Preoperative education: How effective teaching impacts knowledge with the surgical patient. Nursing Thesis and Capstone Projects, Gardner-Webb University.

27-Rosen H, Bergh I et al. (2010): patients experience and perceived causes of persisting discomfort following discharge. BMC nursing Journal, 11(2):9-10.

28- Suhonen $R$ and KiLpi $H$ (2006): Adults surgical patients and information provided to them by nurses: A literature review. Patient 
education and counseling Journals, 61(5):5-15.

29-Brenner P and Donald D (2015): Postoperative care of patients undergoing same-day laparoscopic cholecystectomy. AORN Journal, 102(1):15-18.

30- Bhagirathee p (2013): Patients and nurse's knowledge and understanding of laparoscopy cholecystectomy. Master thesis, University of South Africa.

31-Lithner $M$ and Thomas $M$ (2000): Pre and post-operative information needs. Patient education and counseling Journal, 40(3):29-37.

32-Stergiopoulou A (2014): Pre-operative of information and nurse's role on post-operative recovery in laparoscopic cholecystectomy. Research Article Journal, 7(1):17-21.

33-Elwin (2012): Patients perception regarding nursing care in the general surgical wards at Kenyatta national hospital .Master thesis. School of Nursing Science: university of Nairobi.

34- Donoghue J and Blay N (2006): Source and content of health information for the patients undergoing laparoscopic cholecystectomy .International Journal of Nursing Practice, 12(2):64-70.

35-Alam I (2016): Individualized care in patients undergoing laparoscopic cholecystectomy. International Journal of Medical and Health Research, 2(5):69-72. 